\title{
IMPROVING THE QUALITY OF THE ANALYSIS PROCESS OF TECHNICAL DOCUMENTATION IN AN AEROSPACE ORGANIZATION
}

\author{
Aurel Mihail Tîtút, ${ }^{1,2}$ Alina Bianca Pop ${ }^{3}$ \\ 1 "Lucian Blaga" University of Sibiu, 10, Victoriei Street, Sibiu, România \\ 2 The Academy of Romanian Scientists, 54, Splaiul Independenței, Sector 5, Bucharest, Romania \\ 3 Technical University of Cluj-Napoca, 62A, Victor Babeș Street, Baia Mare, Romania \\ Emails: mihail.titu@ulbsibiu.ro, bianca.bontiu@gmail.com
}

\begin{abstract}
Within the aerospace company in which the study was conducted, the quality management system is fully documented and able to support a permanent control over internal and external activities, which influence the quality of a product or a service. The study highlights all the preventive actions meant to prevent the recurrence of problems, the work systems being standardized, so that they can be maintained. The quality policy is a component part of the organization's policy, and is designed to ensure compatibility with the sector's other sectoral policies. A number of strategies to improve the document analysis process were presented, in order to improve the current way of working. In order to ensure customer satisfaction, the organization adhered to the principles of the APQP methodology and arguments were made that support the importance of implementing this methodology as a measure to prevent defects.
\end{abstract}

Keywords: Quality, Aerospace Industry, Advanced Product Quality Planning (APQP), SWOT Analysis, Methodology.

\section{Introduction}

The aerospace organization in which this study was conducted has as main object of activity the manufacture of extrudates, machined parts, assemblies and subassemblies, and their marketing.

The organization is able to meet current market requirements $[1,2]$ and provide complete valueadded services, by integrating the processes of ingot casting, extrusion, machining, surface treatment and assembly, into a single unit.

The organization uses state-of-the-art technologies during the product manufacturing cycle and a vertical integration strategy in order to continuously improve customer satisfaction. The organization has developed and implemented a quality management system to meet the needs of its customers and to manage operational activities.

The quality management system is in accordance with the international standard AS9100 latest edition and its technical equivalent.

The purpose of the quality manual of the analyzed organization is to document the quality management system to demonstrate compliance with the requirements of the AS9100 standard, customer requirements and applicable legal and regulatory requirements.

The company is under the scope of the quality management system. The processes under the scope of the organization's quality are:
Casting of aluminum alloy bars, mechanically machined parts including surface treatments and assemblies for the aerospace industry, design and development of parts, components and device systems for the aerospace industry, defense and for industrial applications.

This organization supplies exclusively to the aerospace industry aluminum alloy products to all major aircraft manufacturers, subcontractors, machining companies and distributors.

The company's customers are only external. The company supplies parts, assemblies and subassemblies to aircraft manufacturers around the world. The company is a world leader in the market for component manufacturers for the aerospace industry. It has developed over the years and thus has come to provide high quality products, to produce the entire technological flow, from the preparation of alloys to assembly.

At present, it meets the requirements of the market and offers customers a full range of services. The company uses pure aluminum and alloying elements to cast aluminum alloy bars which are then used as raw material for extruded profiles.

The extruded profiles are then heat treated, mechanically machined, coated (surface treatments) and assembled. To carry out this study we started from the SWOT analysis of the organization under analysis. 
The strengths are shown in Figure 1.

\section{Strenghs}

-large number of employees with experience in their field of activity;

•employees with higher education, specialization courses, very good results in the fields in which they work;

-communication and teamwork, the ability to give efficiency and organize working time;

-company known worldwide for the quality of components produced;

-experienced company;

-advanced equipment and technologies that allow the automation of the process and the achievement of superior quality in a short time;

-the processes are in a continuous optimization performed by a dedicated team;

-company that offers stability and security to employees through salaries and bonuses;

-partnerships with the university for employee training.

Figure 1: The strengths of the organization

Weaknesses are shown in the figure 2 .

\section{Weaknesses}

-lack of professional experience or lack of in-depth knowledge in the field in certain departments;

-lack or low presence of personal skills;

-the presence to a greater or lesser degree of negative personal characteristics: shyness, lack of selfconfidence, difficulties in interpersonal communication, lack of motivation and passion for the activity;

-employees without studies who do not always realize the importance of the work they perform;

-many new employees who leave shortly after employment;

-there are situations in which the company has to outsource part of the processes and depends on suppliers in terms of time to produce parts;

-due to outsourced processes, additional expenses appear;

-there is a pressure of production and employees are tempted not to pay attention to all responsibilities to save time;

-mistakes are often remedied without a serious analysis of the root cause and risks;

-the number of staff too small for the pace at which the company grew.

Figure 2: Weaknesses of the organization
The opportunities are shown in the figure 3:

\section{Oportunities}

-hiring staff specializing in the vacant field;

-creating new vacancies, vacancies and the possibility of promotion;

-openness of local authorities and support for enlargement;

-the possibility to use the airport in the area to transport the landmarks more easily;

-by using other materials and other types of equipment, the coverage of aircraft components can be significantly increased;

-labour in the areas where the company operates is cheap compared to competitors.

Figure 3: Company opportunities

The threats are shown in the figure 4 .

\section{Threats}

-competition from other better trained people with longer experience in existing fields;

-reduced opportunities for promotion due to competition with other employees or due to lack of positions;

-the competition is fierce, they fight for each quotation;

- an air incident may cause customers to abruptly stop producing an aircraft;

-the last years have been represented by an increase of large companies in the area, which attracts employees already employed in this company;

-there are no institutions to train staff with higher education specialized in the field in which they work;

-each desired new process requires a lot of preparation, testing of equipment and qualification from customers before the production of parts can begin.

Figure 4: Company threats

\section{Quality Policy}

The organization monitors and analyzes information on internal and external issues. These aspects are monitored and analyzed in the analyzes performed by the management. When planning for the management system, the risks and opportunities to be addressed are taken into account and established to ensure that the quality management system can achieve the intended results, increase the 
desired effects, prevent or reduce undesirable effects, obtain improvements. The organization plans actions to address these risks and opportunities. At the same time, it analyzes how to integrate and implement the actions in the quality management system [1]

All products or services are made strictly to the customer's specifications and requirements and applicable legal and regulatory requirements. Quality objectives have been set at the relevant functions, levels and processes required for the quality management system. Quality objectives are consistent with the quality policy, are measurable, take into account applicable requirements, are relevant to the conformity of products, services and to increase customer satisfaction, monitored, communicated and updated as appropriate. The quality policy within the analyzed company considers the observance of the applicable laws and regulations, to continuously improve the work of each employee, so as to decrease the number of noncompliances, to make employee awareness programs regarding the importance of quality, clear definition of quality objectives and targets for all employees in the company, solving problems in teams so as to highlight the knowledge and experience of each employee, making decisions based on objective data, to promote a culture of quality for all employees so that they be aware that they must comply with all established internal procedures $[3,4]$.

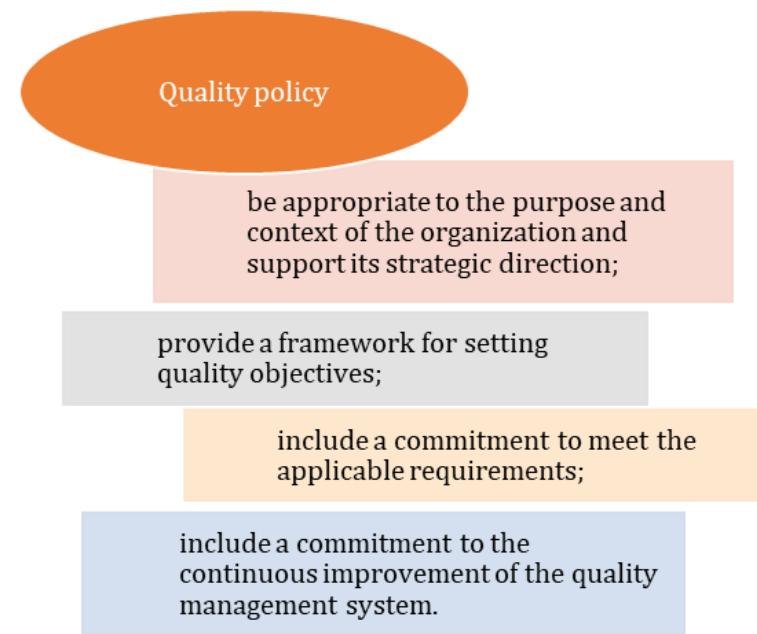

Figure 5: Quality policy requirements [1]

The realization of safe products of the best quality and their timely delivery to external customers can be done by meeting customer requirements, complying with applicable specifications and standards, as well as continuous improvement of the quality management system. Risks and opportunities that may affect the compliance of products and services, as well as the ability to increase customer satisfaction, are established and addressed. The conformity of products and services as well as the performance of on-time delivery are measured and appropriate actions are taken if the planned results are not, or will not be achieved. According to ISO 9001: 2015 "Management at the highest level must establish, implement and maintain a quality policy that meets the requirements presented in Figure 5. Thus, to achieve the strategic direction "in customer satisfaction and business development" there are several priorities in terms of quality that must be imposed and implemented.

\section{Strategies to Improve the Document Analysis Process}

The company's mission is to provide customers with good quality services and products and technical support. To this end, the responsible process engineers draw up the visual aids to help the operators involved in production processes. These visual aids prevent the incorrect assembly of a component and help newcomers a lot. The strategic direction of the company aims at customer satisfaction and at the same time business development. These aspects combine very well when both are performed constantly both individually and together $[5,6]$.

In the company's field of activity, customers place great value on product quality. The situations in which corrections can be made on the product are low and rarely agreed by the customer, which is why the products must rise to the desired standards from the beginning, from the document analysis phase. Through the quality policy and the established objectives, the company works to satisfy the customers, with whom it maintains a close connection through dedicated people who keep them informed with the state of their products. Customers organize visits and audits in the company to see the conditions under which their products are produced, to ensure that everything is carried out to the desired standards and to be able to be sure that the specifications they send are met to the fullest. small detail. For better customer satisfaction it is important for the business to grow. This is applied by the fact that an increase in business could mean lower production costs, both for the company and for its customers. At the same time, the development of the business would represent more opportunities to receive orders for other products from the same customers. One of the most important strategies that should be followed constantly and constantly is the orientation towards the client's requirements. The organization shall ensure that the resources provided are appropriate for the type of specific monitoring and measurement activities undertaken, are maintained to ensure continued suitability for their purpose. An objective that is being worked on and that is desirable to be achieved at all times is to achieve compliant products from the first pass as 
large as possible. This avoids a complaint from the customer and also additional costs. If the parts do not comply with the first attempt, they need to be repaired or redone, which leads to money and time lost. Delays in the delivery of parts to the customer can also occur [2].

Improving Quality means improving the performance of all processes and the results of these processes, in order to ensure better satisfaction of customer needs, in conditions of efficiency. The purpose of the improvement activities is to obtain a higher quality level than planned, respectively the one provided in the standard or specifications. The achievement of such a desideratum is conditioned by the proper development of the activities of planning, organization, training, control and quality assurance.

The harmonization of the influences of suppliers and customers is done respecting the requirements of both parties and having transparency towards each other, so the customer can audit the supplier to ensure that the product was manufactured according to its requirements and specifications, so the customer is open to the supplier. when it encounters any manufacturing problems, incomplete or incorrect documentation. Developing an appropriate information system - for a company to achieve total quality, it must have a well-developed information system in place, so that the connection between customer and supplier is permanent, the customer knows at all times the status of each order and if any certain quality problems with them, so that measures can be taken so that delivery is made on time and to the required quality. Each company must have an internal system in which to track the status of orders in production, processing parameters, available capacity, etc.

Continuous improvement is the principle that means "everything must be done well the first time and every time", i.e. all processes and activities in the organization must be carried out without errors. The organization as a whole and each individual employee must act preventively to avoid the occurrence of defects at the place of activity of each of them. Thus, the "zero defects" principle becomes a real strategy for increasing the quality of the products and the propulsion of the company in the branch of activity [4].

The adoption of a quality management system should be a strategic management decision at the highest level of an organization. The design and implementation of a quality management system for an organization are influenced by objectives, products / services they provide, existing processes, and the size and structure of the organization. Continuous improvement of the overall performance of the organization should be a permanent goal of the organization.

By constantly improving processes, people and how to see the company's business can achieve any goal, customers will be satisfied and real opportunities will be created. The organization aims to act in order to improve the quality management system and to streamline the way it works.

Dedicated people will be responsible for studying and improving the quality management system so that it is as easy as possible for employees to work at high quality standards. At the same time, each department head will work on continuous improvement projects for the area for which he is responsible.

\section{Advanced Product Quality Planning - APQP}

Advanced Product Quality Planning is a set of techniques and tools used to achieve a product quality plan that facilitates the design and manufacture of a product capable of meeting customer requirements $[7,8]$. This way of planning takes into account the opportunities for continuous improvement and prevention that come from the operational implementation plans, internal audits, 8D reports as well as the collection of lessons learned. In order to ensure customer satisfaction, the organization has adhered to the principles of the APQP methodology - to produce, promote and continuously improve safe and reliable products that meet or exceed the requirements of the customer and regulators $[9,10]$. The implementation of APQP is a measure to prevent defects, it is desired that the work be done well the first time and every time.

APQP is a structured method, which ensures that the necessary measures are taken to ensure that new products meet the needs and requirements of customers, the system is based on streamlining product quality and has a preventive approach. APQP interconnects the customer with the designer and the supplier so that everyone knows what is wanted and what the product should look like at the end [9, 10]. The implementation of the APQP methodology has the effect of preventing non-quality at the level of all departments / divisions within the company.

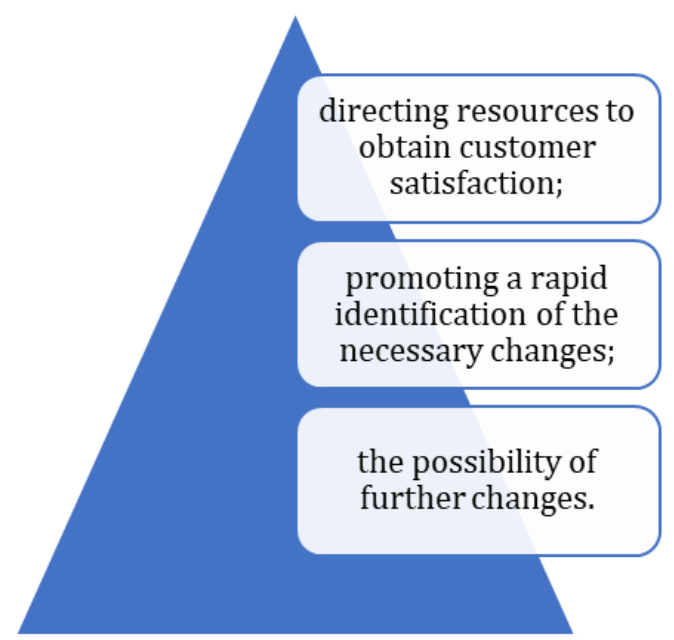

Figure 6: The Benefits of Product Quality Planning [9] 
The benefits of Product Quality Planning are shown in Figure 6 [9]. The purpose of this standard procedure is to describe the processes for defining the applicability of APQP project elements, forming the APQP Team, identifying tasks and responsible people within the project, creating the APQP Project Plan, analyzing the status of the APQP project and concluding the APQP project.

This procedure is applicable in any department within the company when the decision is made to implement an APQP Project for a product or work package. The input data to be considered when determining the applicability of APQP elements include the components presented in figure 7.

The element managers propose to the APQP leader and the Program Manager, a schedule for their tasks, as well as the delivery times of the mileage deliverables.

\section{APQP elements}

\begin{tabular}{|} 
feedback following the management's \\
decision at the highest level to apply the \\
APQP methodology; \\
project entry data and APQP standard \\
requirements; \\
the client's voice, the client's requirements \\
and the format of the project plan; \\
\hline \\
deliverables requested by the customer \\
(including PPAP requirements); \\
\hline initial information related to the detailed \\
structure of the product; \\
\hline initial conceptualization of the production \\
process (including new / unqualified \\
processes identified); \\
produce or buy; If there are any \\
misunderstandings regarding the \\
applicability of the APQP elements, the final \\
Manager; General Manager. \\
\hline
\end{tabular}

Figure 7: The components included by the applicability of APQP elements

Based on these proposals, the APQP Leader will add detailed planning for each element to the APQP Project Plan. The start and end date of each activity must be specified. The delivery date of the product requested by the customer must be clearly defined, together with the date of completion of the FAI and the date of the first deliveries from series production. Those responsible for the elements will be mentioned in the APQP Project Plan.

The APQP project plan will include the planned data for completing the APQP deliverables, aligned with the requirements of the client, program or project.

The project plan will include at least the key deadlines imposed by the client (e.g., first delivery, certification).
The project plan will also provide the frequency of APQP analyzes according to the client's requirement.

When creating the Project Plan, the dates proposed for the completion of the defined tasks and deliverables will also be taken into account. The interdependencies between tasks must also be illustrated. The APQP project plan should illustrate the critical path of the project. The critical path is analyzed and optimized where possible. The 5 APQP phases are defined as follows in table 1 . If a company focuses on the quality of the finished product, but not on the quality of the intermediate stages, on the quality of the relationship with the customer, but not on the quality of the relationship between employees 
within the company, on compliance with delivery terms. can speak of total quality $[11,12]$. These cases may represent the application of quality in some aspects of the functioning of that company. Quality must start with people, which means that this concept must be stated among all employees and they must believe in the importance of quality in their work, so that they apply it constantly. In this way, products, the relationship with customers and suppliers, opportunities will be improved and risks will decrease [13].

\begin{tabular}{|c|c|c|c|c|}
\hline $\begin{array}{l}\text { Phase } 1 \text { - } \\
\text { Planning }\end{array}$ & $\begin{array}{c}\text { Phase } 2 \text { - Product } \\
\text { design and } \\
\text { development }\end{array}$ & $\begin{array}{c}\text { Phase } 3 \text { - Process } \\
\text { design and } \\
\text { development }\end{array}$ & $\begin{array}{c}\text { Phase } 4 \text { - Product } \\
\text { and process } \\
\text { validation }\end{array}$ & $\begin{array}{l}\text { Phase } 5 \text { - } \\
\text { Production }\end{array}$ \\
\hline $\begin{array}{l}\text { The main } \\
\text { objective of this } \\
\text { phase is to } \\
\text { collect all the } \\
\text { input elements } \\
\text { and to prepare } \\
\text { the project } \\
\text { framework } \\
\text { (product } \\
\text { concept, process } \\
\text { prerequisites, } \\
\text { key roles, key } \\
\text { tasks and } \\
\text { deadlines). }\end{array}$ & $\begin{array}{l}\text { The main objective } \\
\text { is to design the } \\
\text { product taking } \\
\text { into account all } \\
\text { identified } \\
\text { requirements and } \\
\text { risks. }\end{array}$ & $\begin{array}{l}\text { The main objective is } \\
\text { to design the } \\
\text { manufacturing and } \\
\text { assembly processes } \\
\text { taking into account } \\
\text { all the requirements } \\
\text { and risks identified. }\end{array}$ & $\begin{array}{l}\text { The main } \\
\text { objective is to } \\
\text { validate that the } \\
\text { process produces } \\
\text { the specified } \\
\text { product while } \\
\text { meeting all } \\
\text { requirements } \\
\text { and producing } \\
\text { the quantity } \\
\text { requested by the } \\
\text { customer. }\end{array}$ & $\begin{array}{l}\text { The main objective } \\
\text { is to monitor } \\
\text { performance against } \\
\text { the targets set for } \\
\text { series production, to } \\
\text { reduce variation, to } \\
\text { manage non- } \\
\text { conformities, to } \\
\text { continuously } \\
\text { improve } \\
\text { performance and to } \\
\text { pass on the lessons } \\
\text { learned in new } \\
\text { projects and in the } \\
\text { APQP. }\end{array}$ \\
\hline
\end{tabular}

Those who have to set the tone for quality and support this concept in the company are the management representatives. They will be able to impose the way things will be conducted, they will be able to support all the causes to be solved to ensure the desired quality, they will be able to allocate resources, create functions that will be responsible for implementing activities in the required management directions. This creates an environment that makes people's work easier and helps them see quality as a need and something they can't work without.

\section{Conclusions}

The starting point of this paper was a brief presentation of the company with its field of activity in the aerospace industry. For this company that deals with the production of extruded aluminum components for the aerospace industry, a SWOT analysis was presented, after which it was established that the organization has some strengths that it must take advantage of in the future and keep them.

At the same time, there were a number of weaknesses that should be addressed in order to reduce them. The identified opportunities are important and must be achieved as soon as possible, taking into account the fact that in this field the competition is strong and the loss of place in the ranking can occur at any time, but the recovery of lost ground is very difficult. This can also be seen from the identified threats which should be reduced and kept at bay by creating new opportunities and maintaining superior quality so that the threats lose their breadth.

A number of strategies were presented to improve the document analysis process in order to improve the current way of working. It is important that each department within the company keeps pace with the pace at which the organization grows and adapts accordingly. Taking into account quality standards, customer desire and requirements, internal ambitions and the company's strategy to meet customer needs and grow further, the company has set quality objectives that are analyzed and reported monthly to management. At the same time, goals have been set for each department or area of a department. For them, there are people designated to ensure that they are achieved and that measures are proposed if they are not at the desired level.

Strategies have been formulated and improvement actions have been proposed at company and department level. Continuous improvement actions can be carried out within the department during the actual work, can be proposed to management and approved, can be proposed through projects by the department specially designated for this purpose. The analyzed company addresses to a large extent the problems in the form of prevention and adopts a thinking based on risk anticipation. 
There are examples that show that the organization has taken action and is constantly working to prevent and detect nonconformities rather than acting after they have been discovered. This way of working is also promoted by the quality standards that, with the last revision, have given more importance to risks.

\section{References}

[1] Alsaqaf, W; Daneva M; Wieringa R; Quality Requirements in Large-Scale Distributed Agile Projects - A Systematic Literature Review. In: Grünbacher P., Perini A. (eds) Requirements Engineering: Foundation for Software Quality. REFSQ 2017. Lecture Notes in Computer Science, vol 10153. Springer, Cham. https://doi.org/10.1007/978-3-319-54045-0_17, Published: 2017

[2] AECMA. 1986 . A guide for the preparation of aircraft maintenance documentation in the international aerospace maintenance language . Derby , UK BDC Publishing Services, Published: 1986.

[3] Kim, Hongbum; Jo, Yuri; Lee, Daeho; R\&D, Marketing, Strategic Planning, or Human Resources? Which CEO Career Is Most Helpful for the Economic Sustainability of ICT Startups in South Korea?" Sustainability 13, no. 5: 2729. https://doi.org/10.3390/su13052729, Published: 2021

[4] Morris, M; Retrieved 7 7, 2013, from Advanced Product Quality Planning: static.squarespace.com, 2012.
[5] Rajamani, M and Punna, E; Enhancement of Design for Manufacturing and Assembly Guidelines for Effective Application in Aerospace Part and Process Design, SAE Technical Paper 2020-01-6001, https://doi.org/10.4271/202001-6001, Published: 2020.

[6] Reiter, E; Mellish, C and Levine, J; Automatic generation of technical documentation. Applied Artificial Intelligence., Taylor \& Francis 9(3): 259-287, Published: 1995.

[7]Advanced Product Quality Planning (APQP) Production Part Approval Process (PPAP), Guidance Material for International Aerospace Standard 9145, IAQG, SCMH Section 7.2.3 APQP (2017)

[8]SR EN ISO 9001:2015 Quality management systems Requirements.

[9]AS9100D: Quality Management Systems Requirements for Aviation, Space and Defense Organizations. SAE International..

[10] SAE AS 9145:2016 - Aerospace series Requirements for Advanced Product Quality Planning and Production Part Approval Process.

[11] Kumar, A; Business Process Management, First Edition. New York: Routledge: Taylor \& Francis Group, 2018.

[12] Kock, N; Systems Analysis and Design Fundamentals: A Business Processs Redesign Approach. Thousand Oaks, CA: Sage Publications, 2006.

[13] Dumas, M; La Rosa, M; Mendling, J \& Reijers, H. A; Fundamentals of Business Process, Management. Springer, 2013. 